\title{
La cárcel de Jerez de los Caballeros (Badajoz) durante el siglo XIX
}

\author{
FJ Suárez-Guzmán, D Peral-Pacheco
}

Médico de Familia y Profesor Colaborador de la Universidad de Extremadura. Doctor en Medicina y Profesor Titular de la Universidad de Extremadura.

\section{RESUMEN}

En el presente artículo hemos estudiado la coyuntura de los presos en las cárceles españolas en general y de Jerez de los Caballeros en particular. Para ello hemos analizado la documentación del Archivo Histórico Municipal de Jerez, así como publicaciones actuales y de la época. Como resultado hallamos que las condiciones de los edificios rozaban la ruina, los enseres estaban en pésimo estado o simplemente no existían y la situación higiénico-sanitaria rayaba en lo inhumano. Las patologías de los presos podían suponer una amenaza para la población general, al existir el riesgo de extenderse en forma de epidemias, aunque no se sabe casi nada de ellas. Los esfuerzos de las autoridades fueron escasos y poco efectivos, debido a las carencias económicas, para subsanar los problemas estructurales y de salud. La asistencia médica corría a cargo de los facultativos locales a cambio de unos honorarios.

Palabras clave: Prisiones; Epidemia; Prisioneros; Salud Pública; Higiene; Jerez de los Caballeros; Historia de la Medicina; España.

\section{THE PRISON OF JEREZ DE LOS CABALLEROS (BADAJOZ) IN THE 19TH CENTURY}

\begin{abstract}
This article considers the situation of prisoners in Spanish jails, taking the circumstances of the inmates at the prison of Jerez de los Caballeros as a particular example. Documents from the Jerez Municipal Historical Archives were studied along with other contemporary and more current publications. The results show that the conditions of the buildings bordered on the ruinous, the facilities were in poor condition or unavailable and health and hygiene were practically inhumane. Pathologies of the prisoners posed a threat to the general population, as there was the risk of outbreaks of epidemics, but almost nothing is known about them. Efforts by the authorities to remedy structural problems and health problems were few and mostly ineffective due to due to economic difficulties. Medical assistance was provided by local doctors in exchange for a fee.
\end{abstract}

Keywords: Prisons; Epidemics; Prisoners; Public Health; Hygiene; Jerez de los Caballeros; History of Medicine; Spain.

Texto recibido: $27 / 10 / 2013$

Concepción Arenal, socióloga gallega, fue una gran defensora de los derechos de los presos en el s. XIX, como Visitadora General de prisiones de mujeres, tuvo la ocasión de recopilar en algunas de sus publicaciones las condiciones insalubres de las cárceles de la época, las cuales no eran más que lugares destinados a confinar personas castigadas por la sociedad. Refiere que:
Texto aceptado: 6/02/2014

"Los presos ocupan lugares lóbregos, búmedos, reducidos, faltos en fin de toda condición bigiénica; carecen de cama y de vestido, y para cubrir su desnudez se implora, muchas veces en vano, la caridad pública. Hay casos de enfermos graves hasta el punto de administrárseles los sacramentos, cuya cama es el suelo, mullido solamente con algún mugriento harapo; por no baber 
enfermería en la cárcel, la persona que muere a consecuencia de este horrible tratamiento es acaso declarada inocente. En su tumba desconocida no se lee descripción alguna, pero podría gravarse este epitafio: Aqui yace la víctima inocente de una sociedad culpable"1.

Las cárceles en aquellas fechas estaban destinadas a recluir a aquellas personas, delincuentes o no, que la sociedad como heredera del Antiguo Régimen consideraba oportuno. En sus orígenes medievales los gastos eran sufragados por donaciones, aunque con el devenir de los tiempos esta forma de caridad era insuficiente y se tenía que recurrir, una vez más, a los presupuestos municipales. Este carácter benéfico, mediante una confusa piedad, mantiene a personas marginadas y paupérrimas de forma lastimosa, producto de una sociedad clasista ${ }^{2}$.

El número de presos era muy variable, encontrándose entre ellos gentes marginales que delinquían por auténtica necesidad, hacinados y en condiciones con frecuencia insalubres. En el Archivo Histórico Municipal de Jerez de los Caballeros (AHMJC) encontramos cómo los desgraciados presos de la cárcel nacional, el 25 de abril de 1863, solicitan auxilio al Sr. Gobernador pues “...de lo contrario seremos bictima de la miseria en esta mansión de horror..." 3 En estas circunstancias se agravaban patologías que previamente sufrían. El 27 de marzo de 1887 el preso Alberto Ramírez expone que se halla cumpliendo condena por un delito de lesiones, por lo cual se la ha agravado el reuma que padecía con anterioridad, como certifica el facultativo D. Eladio Rubio, debido a las malas condiciones higiénicas del establecimiento, no experimentado mejoría pese a los tratamientos prescritos, por lo cual solicita su traslado al hospital de la ciudad. La solicitud viene acompañada de una declaración de D. Eladio dando fe de los hechos ${ }^{3}$.

Pascual Madoz recoge la estadística criminal del partido de Jerez:

"Los acusados de este part. Jud. En el año de 1843, fueron 126, de los que resultaron absueltos de la instancia 15, y libremente 6; penados presentes 90; contumaces 15; reincidentes en el mismo delito 4, y en otros diferentes 14: del total de procesados, 21 contaban de 10 á 20 años de edad; 65 de 20 á 40, y 25 de 40 en adelante: 110 eran hombres, y 16 mujeres; 54 solteros y 57 casados; 30 sabian leer y escribir, 81 carecian de toda instruccion; uno ejercía profesión científica ó arte liberal, y 110 artes mecánicos; de los 15 reos prófugos no consta la edad, ni el estado, ni la educacion, ni el ejercicio. En el mismo periodo se perpetraron 62 delitos de bomicidio $y$ de heridas, con 3 armas de fuego de uso lícito; uno de ilícito, 9 de armas blancas permitidas, una probibida y 10 instrumentos contundentes" 4 .

La base de nuestra investigación ha sido el análisis y estudio de los legajos del AHMJC, en busca de información relacionada con la cárcel municipal y sus coyunturas, así como publicaciones de la época y actuales.

La vida en estos establecimientos era tremendamente dura e insalubre. Según Sánchez Granjel a finales del s. XVIII y principios del XIX, el estado higiénico de algunas prisiones madrileñas fue tan deplorable que fueron tildadas de mansiones de horror $y$ de llanto, y lugares de inmundicias, de putrefacción $y$ de dolor. Estas paupérrimas condiciones higiénicosanitarias, añadidas al hacinamiento que sufrían los presos, conllevaba elevadas tasas de incidencia de patologías como la tuberculosis, viruela, sarna, tifus y tiña. El Profesor Granjel hace referencia a una reflexión publicada en 1792 por Ximénez de Lorite y al informe escrito en 1801 por Ruiz de Luziriaga tras una visita efectuada a los penales de la Corte de Madrid $^{5}$.

El Gobernador Político provincial reflexiona el 22 de junio de 1814, sobre lo inútil de los esfuerzos de detener delincuentes, si la seguridad de las prisiones no evita las fugas. Por lo cual la cárcel de la localidad debe mejorar su seguridad, capacidad, ventilación y salubridad, debiendo informar si son precisas obras, su cuantía, o si es necesario construir una nueva; teniendo en cuenta que la capacidad debe ser suficiente para acoger con comodidad al número de presos que suele haber, y poder facilitarles realizar algún trabajo de mano para que se distraigan, y puedan obtener medios para subsistir con menos miseria. Al lado de la cárcel debe haber una sala donde el Juez realice sus visitas ${ }^{6}$.

Ya en 1835, el 18 de junio, la Corporación estima que las reformas no garantizan la completa salubridad, al estar encima de la cárcel el Real Pósito, por lo cual carecerá de ventilación y sufrirá humedad. Así mismo, la capacidad es para cincuenta o sesenta hombres y mujeres, ya que sólo existe una galería pequeña con tres calabozos pequeños, dos cuartos para las mujeres, una sala judicial y un patio, todo muy reducido, por lo cual la prisión está muy expuesta a contagios o epidemias. Por todo lo cual el Ayuntamiento decide solicitar al Gobernador Civil un nuevo edificio ${ }^{7}$. 
En 1861 el alcaide de la prisión del partido judicial de Jerez, Manuel Pablo Ramos, se dirige al Ayuntamiento el 5 de mayo para informar del estado ruinoso del establecimiento, en el cual se encuentran en ese momento treinta y cinco presos, debido a la humedad e insalubre estado de las dependencias, lo cual hace temer que se desarrolle una epidemia que afecte a los reclusos o a la población jerezana. Añade además que el edificio ofrece unas escasas condiciones de seguridad debido a su antigüedad, por lo cual existe la posibilidad de fuga por escalamiento. De esta manera, solicita se realicen las obras oportunas o se levante una nueva prisión. Ese mismo día la Corporación decide instruir el correspondiente expediente oyendo para ello a la Junta de Sanidad y al Sr. Juez de Primera Instancia del partido ${ }^{8}$.

El día 6 de junio informa la Junta Municipal de Sanidad por medio de dos de sus miembros los facultativos, D. Ildefonso Díaz Caballero y D. Sebastián Ramírez, de las pésimas condiciones del local: escasa capacidad, falta casi completa de ventilación y de luz al estar casi subterráneo, humedades importantes y carencia de las más fundamentales condiciones de salubridad e higiene. La Junta de Sanidad recomienda la construcción de una cárcel nueva, que reúna todas las condiciones anteriormente exigidas, así como la seguridad adecuada ${ }^{8}$.

En cuanto al informe del Juez de $1^{\text {a }}$ Instancia, éste comenta que respecto a la salubridad ya se ha pronunciado la Junta de Sanidad, y poco más hay que añadir sobre "...esa pocilga, que no merece otro nombre, pues hasta su pequeña puerta lo revela, que hay que traspasarla, poco menos que de gatas, para convencer su insalubridad, y repugnancia á permanecer en el ni por un cuarto de ora" el riesgo de la aparición de enfermedades epidémicas en la población reclusa, que incluso pueden afectar al resto de la población. Monlau refiere que las cárceles eran consideradas establecimientos insalubres de primera clase por su capacidad de infestar el aire de poblaciones; por lo cual se tomaban ciertas medidas como: llevar el pelo muy corto, hacerles tomar un baño de limpieza de vez en cuando, la alimentación será sana y en cantidad, usar vestidos vastos sin tinte para que se vean las manchas; el estado de cautiverio o encarcelamiento acorta la vida de 17 a 35 años, una detención de 10 años equivale a $3 / 7$ de una sentencia de muerte?

Según el Real Decreto del 4 de octubre de 1877 respecto a la Reforma Penitenciaria, se considera la creación de una Junta de Reforma de Cárceles en cada pueblo cabeza de partido, pero no se plantea la construcción de un nuevo edificio, sino que se con- sidera reparar el antiguo a pesar de su estado y de la cantidad de reformas que necesita. Este Real Decreto publicado en el Boletín Oficial de la Provincia del 17 de octubre de 1877, estaba firmado por el Ministro de la Gobernación D. Francisco Romero Robledo, e incluía un plano como modelo de instituciones penitenciarias diseñado por el arquitecto $\mathrm{D}$. Tomás de Aranguren.

Así pues, en las últimas décadas ni se construyó una prisión nueva, ni se volvió a hablar de humedad, ventilación, condiciones insalubres, limitándose la Corporación a reparar desperfectos y realizar algunas mejoras, más de mobiliario que otra cosa.

Como es lógico este tipo de establecimientos necesita de un personal encargado de gestionarlo y mantenerlo; de esta manera, el 20 de octubre de 1896 el Ayuntamiento decide, para el buen servicio de la cárcel y previa lectura de las solicitudes presentadas, nombrar como alcaide interino a D. Manuel Ramos Lamego, que ya lo había sido anteriormente; para mandadero a Bernabé Barranca Pitel; para surtir agua diariamente a Blasa Galván Gómez; y para maestro barbero con obligación de afeitar, sangrar y cortar el pelo a todos los presos, a Baltasar Morero Neila ${ }^{10}$.

En estas fechas no eran extraños los abusos o injusticias. De esta manera, hemos podido recopilar el 24 de julio de 1810, el testimonio del encarcelamiento del alguacil Matías Hernández, poniéndosele incluso el cepo, por negarse a embargar un bagaje para un caballero oficial, siendo esta misión responsabilidad del Ayuntamiento, motivo por el cual el Alcalde solicita al Juez su liberación ${ }^{11}$.

Así mismo, las penas impuestas en aquellas fechas, hoy en día nos parecerían totalmente desproporcionadas. Sirva de ejemplo el caso de José López Galván y José Riera Barriga, sospechosos del hurto de cinco cerdos y de caminar sin pasaporte, condenados el 11 de junio de 1851 a la pena de seis años de presidio menor e inhabilitación absoluta para cargos y derechos políticos doce años; y treinta meses de presidio convencional e inhabilitación sesenta meses, respectivamente, así como al pago de las costas pero no de la indemnización de los perjuicios por haber renunciado el propietario de los cerdos ${ }^{12}$.

No sólo el edificio era una miseria, sino que también los enseres brillaban por su ausencia, lo más indispensable para la vida humana faltaba en estos lugares, lo que contribuía a crispar aún más a los desgraciados que tenían el infortunio de caer presos. Los camastros, cuando los había, eran jergones de paja llenos de suciedad y piojos, a veces ubicados en el mismo suelo, húmedo y lleno de excrementos; depó- 
sitos de madera para la recogida de residuos fisiológicos, cántaros o vasijas para el agua, que alternaban su uso habitual con fines medicinales. Los tratamientos médicos empleados eran fundamentalmente de uso tópico: curas de heridas superficiales, emplastos, ungüentos, etc., que suponían un elevado porcentaje del gasto farmacéutico. Los enemas y refrescos derivados de productos naturales como el vino, el azúcar o los limones, dietas especiales basadas en la leche, el chocolate o los bizcochos, constituían capítulos de gran importancia ${ }^{13}$.

Como es natural la figura de mayor peso en estos establecimientos era la del alcaide, se solía nombrar a una persona de la localidad, de total confianza y autoridad y plenos poderes para hacer cumplir las ordenanzas y legislación vigentes. El nombramiento lo realizaba el Gobernador Civil, y a veces se autorizaba a la Alcaldía, eligiendo a licenciados de la Guardia Civil ${ }^{14}$. Entre sus funciones estaba la limpieza y aseo del recinto, la elaboración de los presupuestos anuales y el efectuar semanalmente una vista para la inspección de la cárcel, junto al Alcalde de la villa, según la Real Orden del 8 de mayo de $1853^{15}$. Aunque el documento está muy deteriorado, podemos analizar el acta, que posteriormente se enviaba al Gobernador Civil, de la realizada a las once de la mañana del 13 de septiembre de 1879 por el Alcalde D. Baltasar Muro, dice así:

“...comparecen ante su presencia todos los presos á los cuales interrogó sí se hallaban socorridos, y contestando afirmativamente, pasó después á los distintos departamentos del Establecimiento y se cercioró de que cada uno de dichos presos ocupaba el que le correspondía con arreglo á la ley; que los penados cumplian las condenas impuestas, y por último que referido local se encuentra en el mejor estado de limpieza posible"16.

El 14 de agosto de 1852, el sueldo del único empleado de la prisión del partido, el alcaide Ramón Planas, nombrado el 16 de febrero del 1848, tomando posesión ese mismo día, consistía en dos mil doscientos reales de vellón ${ }^{17}$. Más adelante, el 31 de diciembre de 1875 , hallamos otra relación del escaso personal, Cuadro 1.

En el Cuadro 2 podemos estudiar el presupuesto para el año económico de 1867-68. El total se procede a dividir entre los diferentes pueblos del partido, al no haber dinero en las arcas ${ }^{18}$.

Comenta Sánchez Granjel que en la Granada renacentista había ordenanzas municipales que ordena-

Cuadro 1. Relación del Personal de la Prisión del Partido Judicial de Jerez de los Caballeros en el Año de 1875

\begin{tabular}{llcc}
\hline Nombre & Cargo & Dotación (en pesetas) & Nombramiento \\
\hline Fernando Méndez Lanchazo & Alcaide & 550 & 27-I-75 \\
\hline Fco. González Garrido & Barbero & 100 & 1-I-46 \\
\hline Margarita Cortés & Aguadora & 210 & $15-$ VIII-75 \\
\hline
\end{tabular}

Fuente: AHMJC. Administración de Justicia. Cárcel y Presos. Legajo 1. Carpeta 20. Sin foliar.

Cuadro 2. Presupuesto de Gastos de la Cárcel del Partido Judicial de Jerez de los Caballeros para el Año Económico de 1867-68 (en escudos)

\begin{tabular}{lcc}
\hline Concepto_ & Cantidad & $\%$ \\
\hline Relación no 1: Personal & 333,000 & 13,8 \\
\hline Relación no 2: Material: gastos de oficina, alumbrado, limpieza, ropas y útiles & 100,00 & 4,2 \\
\hline Relación no 3: Honorarios facultativos por autopsias y reconocimiento por mandato judicial & 100,000 & 4,2 \\
\hline Relación no 4: Mantenimiento de 25 presos pobres que se calcula podrían necesitar socorro & $1.847,000$ & 77,0 \\
\hline Relación no 5: Conducción y traslado de 60 presos que se calcula había de tránsito & 20,000 & 0,8 \\
\hline Total & $2.400,000$ & 100,0 \\
\hline
\end{tabular}

Fuente: AHMJC. Administración de Justicia. Fondos Carcelarios. Presupuesto Carcelario. Legajo 1. Carpeta 1. Sin foliar. 
ban hubiese un físico “...que cura los pobres de la Cárcel” ${ }^{19}$, al cual se dotó con cinco mil maravedíes anuales. De ahí la necesidad de incluir un facultativo en la relación de personal.

En cuanto a los alcaides de la prisión decir que sólo tenemos constancia de dos, el mencionado D. Ramón Planas y D. Manuel Pablo Ramos Lamego, el cual fue nombrado el 17 de agosto de 1860 permaneciendo en el cargo hasta el 1897, desconocemos los últimos años del siglo si continuó o no, ya que no aparece en los documentos, pasando a denominarse el cargo vigilante de la cárcel con un sueldo de 999 pese$\operatorname{tas}^{20}$. Sus emolumentos estaban consignados en la Relación $\mathrm{n}^{\mathrm{o}} 1$, junto con el maestro barbero sangrador, el mandadero, el aguador, amanuense y en el 1900 el capellán. Esta relación de personal varió con los años incluyéndose en la última década un profesor facultativo con 250 pesetas de dotación, desde 1893 según nos consta, y posteriormente en 1897 pasó a denominarse de medicina y cirugía, aumentándose a 500 pesetas el sueldo en 1900. Aunque con grandes retrasos a la hora de efectuar los pagos.

Ya vimos cómo los intentos para construir una nueva prisión quedaron en el olvido, realizándose únicamente remiendos y parches en las vetustas y semiderruidas instalaciones. La mayor parte de los presupuestos se los llevaba la albañilería, la carpintería y la cerrajería. En otras instituciones existían pequeñas partidas para blanqueo, compra de vinagre, pólvora, azufre, espliego, destinados a la purificación y desinfección ambiental, amén de la compra de aceite indispensable para el alumbrado. Refiere Rodríguez Sánchez que en la prisión de la Audiencia de Cáceres, el consumo de pólvora y azufre para la purificación del aire se situaba entre dos y cuatro papeles de pólvora y de una a tres libras de azufre por mes. El sahumerio de espliego sólo se hacía cuando los miembros de la Audiencia pasaban a las distintas galerías para tomar declaración a los detenidos ${ }^{13}$.

Como hemos dicho la situación de los reos en las prisiones era lamentable, los estados de miseria en los que se hallaban rozaban lo inhumano, abarcando no sólo el edificio, sino aspectos tan esenciales como la manutención. La escasez o mala calidad de la comida, ha sido frecuente motivo de motines a lo largo de la historia penitenciaria. Como ejemplo tenemos la circular $\mathrm{n}^{\circ} 2$ de la Real Sala del Crimen de la provincia, comunicando a sus diferentes pueblos, la orden de reducir a doce cuartos el socorro de los presos, para el cual se tomarán primero los bienes de éstos si los tuvieren, y si no de los fondos públicos, en caso de no tener vecindad se repartirá entre los pueblos del partido, tal y como contempla la Real Orden del 14 de agosto de 1828. Como era de esperar la respuesta del Ayuntamiento fue la consabida falta de fondos.

Aunque la manutención era solamente para los presos pobres, debido a su carencia absoluta de posibilidades económicas, realmente se socorría a todos los recluidos, con la gran carga que suponía para las arcas de los Ayuntamientos, siempre en estado paupérrimo. De esta manera, el 3 de febrero de 1831 se hace constar, que los dieciséis presos pobres de la cárcel carecen de auxilios y socorros para su subsistencia, sin que los cortos fondos ni las diligencias hechas, implorando la piedad de los vecinos pidiendo de puerta en puerta, baste para su manutención. Al no ser responsabilidad de la Corporación la manutención de los presos, y no pudiendo cargar ninguna contribución al pueblo, aunque se les auxiliará en cuanto se pueda, se decide consultar con el Intendente de la provincia el 5 de mayo de 1830 “...para que se digne aclarar si los Ayuntamientos están o no obligados a subministrar los socorros necesarios a los presos [...] y en caso de que sea peculiar del Aymo. la espresada obligación se sirva manifestar de que fondos ha de salir los socorros"21.

La Diputación Provincial, el 27 de marzo de 1837, ordena que se incoe un expediente para el socorro de los presos pobres correspondientes al juzgado del partido, según la Real Orden del 3 de mayo del 1837 inserta en el Boletín Oficial de la provincia del 13 de junio, para el reparto de la cantidad que corresponde a cada pueblo. El Ayuntamiento decide enviar una comunicación al Sr. Juez de Primera Instancia, para que informe del número de presos que han sido socorridos en la cárcel nacional en el año anterior, especificando el pueblo, desde qué época se comenzó a recibir la ayuda y la carencia absoluta de bienes de los reos ${ }^{22}$.

Una Real Orden del 8 de marzo de 1839 decreta que tanto las estancias hospitalarias, como la manutención de los presos pobres, corran por cuenta de los pueblos del partido, lo que alivia las penurias económicas relativamente. De esta manera, el Ayuntamiento carga trimestralmente a la Diputación los gastos de la cárcel, aunque con frecuencia existían demoras en los pagos.

Ya en 1853, nuevamente el Gobierno Civil se dirige a la Corporación para ordenar la recaudación de 7.000 reales entre los diferentes pueblos del partido, que junto con los 3.846,28 sobrantes del año pasado, servirán para atender el socorro de los reclusos pobres $^{23}$. En el Cuadro 3 hemos plasmado los importes correspondientes a cada localidad. Como es lógico las poblaciones más importantes y con mayor número de habitantes aportaban más, como es el caso de Jerez con el $27,7 \%$, y Oliva con el $15,0 \%$. 
Las cantidades invertidas por cada preso a lo largo del s. XIX oscilaron entre uno y tres reales al día, con los cuales se pagaba el rancho diario. Rodríguez Sánchez y Marcos Arévalo comentan la existencia de dos tipos de rancho, el de los presos enfermos con un mayor contenido proteico, y el de los presos comunes. En 1811 el puchero de enfermos estaba constituido por diez cuartos de arroz, nueve y medio de carne, siete de tocino, una suerte de pan de diez y nueve cuartos, un cuarto de sal y lumbre, entre 1831 y 1835 la ración diaria estaba compuesta de 1/2 ración de garbanzos, de tres a ocho libras y de seis a veinticuatro onzas de tocino, una libra diaria de pan, de 1/5 a 1/2 arroba diaria de carbón y de $1 / 4$ de sal y pimienta ${ }^{24}$.

Cuadro 3. Reparto Económico entre los Distintos Pueblos del Partido Judicial de Jerez de los Caballeros para el Sostenimiento de la Cárcel en el Año de 1853

\begin{tabular}{lcc}
\hline Pueblos & Cantidad (en reales) & $\%$ \\
\hline Barcarrota & $1.084,20$ & 15,5 \\
\hline Jerez de los Caballeros & $1.934,22$ & 27,7 \\
\hline Oliva de Jerez & $1.257,22$ & 18,00 \\
\hline Salvaleón & 731,32 & 10,4 \\
\hline Salvatierra & 679,10 & 9,7 \\
\hline Valencia del Mombuey & 207,12 & 3,0 \\
\hline Valle de Matamoros & 325,20 & 4,6 \\
\hline Valle de Sta. Ana & 409,40 & 5,8 \\
\hline Zahínos & 369,30 & 5,3 \\
\hline Total & 7.000 & 100,00 \\
\hline
\end{tabular}

Fuente: AHMJC. Administración de Justicia. Cárcel y Presos. Legajo 1. Carpeta 14. Sin foliar. 23-III-1853.

Al igual que en otras prisiones, el potaje de garbanzos, el tocino, la carne y el pan eran fundamentales en las dos raciones diarias que se suministraban a los reos; la primera al inicio de la mañana y la segunda por la tarde $\mathrm{e}^{25}$.

Un concepto interesante era el de los presos transeúntes, éstos eran socorridos con una pequeña cantidad económica, a su llegada por la tarde o por la noche, se les abonaba su parte de la comida de la mañana y se les daba alojamiento con el resto de los reclusos. Una Real Orden del 13 de septiembre de 1849, ordenaba a los Ayuntamientos donde pernoctasen, a atender a estos reos con sesenta maravedíes. El traslado de los presos de una cárcel a otra era efectuado por la Guardia Civil, en la Gaceta de Madrid del 27 de marzo del 1831 se puede leer: Se hace responsable a las justicias de los pueblos de la seguridad de los reos que se conducen de una cárcel a otra, también existían partidas destinadas a sufragar los gastos de las conducciones de estos reclusos ${ }^{26}$, y sus estancias en el Hospital por "carecer la cárcel de enfermería"27.

Las cantidades económicas destinadas al socorro de los presos pobres, fue variando con los años, de esta manera el 16 de febrero del 1870 se reduce de 200 milésimas de escudo a $150^{28}$; mientras que en el 1900 era de 50 céntimos de peseta por día ${ }^{29}$.

Dentro de los presupuestos municipales existían unas cantidades destinadas al pago de los “...horarios que devengan los facultativos por autopsias y reconocimiento por mandato judicial" 30 , en la Relación n ${ }^{\circ} 3$ dotada con 100 escudos, desapareciendo después del 1870-71; reapareciendo en 1893-94, como ya dijimos, en la Relación $n^{\circ} 1$ como profesor facultativo, con un sueldo de 250 pesetas. En el Cuadro 4 comprobamos los presupuestos totales, y las cantidades destinadas a gastos facultativos, los dos primeros en escudos y el resto ya en pesetas. Como se aprecia carecemos de datos de varios periodos, y desde 1871 a 1893 no se presupuesta ninguna cantidad para este concepto, no cambiando la cantidad hasta el final del siglo.

Cuadro 4. Presupuestos de la Cárcel del Partido Judicial de Jerez de los Caballeros en el Periodo de 1867-1900.

\begin{tabular}{lccc}
\hline Ejercicio Económico & $\begin{array}{c}\text { Presupuesto } \\
\text { Total }\end{array}$ & $\begin{array}{c}\text { Presupuesto } \\
\text { Facultativos }\end{array}$ & $\%$ \\
\hline $1867-1868$ (en escudos) & $2.400,000$ & 100,000 & 4,2 \\
\hline $1869-1870$ (en escudos) & $3.000,000$ & 100,000 & 3,3 \\
\hline $1870-1871$ (en pesetas) & $7.500,00$ & 250,00 & 3,3 \\
\hline $1875-1876$ (en pesetas) & $7.500,00$ & - & - \\
\hline $1882-1883$ (en pesetas) & $5.684,00$ & - & - \\
\hline $1883-1884$ (en pesetas) & $5.684,00$ & - & - \\
\hline $1884-1885$ (en pesetas) & $5.684,00$ & - & - \\
\hline $1885-1886$ (en pesetas) & $5.684,00$ & - & - \\
\hline $1886-1887$ (en pesetas) & $4.412,57$ & - & - \\
\hline $1887-1888$ (en pesetas) & $4.722,77$ & - & - \\
\hline $1889-1890$ (en pesetas) & $4.283,16$ & - & - \\
\hline $1893-1894$ (en pesetas) & $8.984,25$ & 250,00 & 2,8 \\
\hline $1896-1897$ (en pesetas) & $7,108,00$ & 250,00 & 3,5 \\
\hline $1897-1898$ (en pesetas) & $9.100,99$ & 250,00 & 2,7 \\
\hline $1898-1899$ (en pesetas) & $15.321,50$ & 250,00 & 1,6 \\
\hline $1899-1900$ (en pesetas) & $10.606,60$ & 250,00 & 2,4 \\
\hline (en & & - & - \\
\hline
\end{tabular}

Fuente: AHMJC. Administración de Justicia. Fondos Carcelarios. Presupuesto Carcelario. Legajo 1. Carpetas 1-19. Sin foliar. 
En el Cuadro 5 analizamos las cantidades presupuestadas para gastos en medicinas. Al igual que en el anterior cuadro, en éste hasta el periodo del 18851886 no encontramos partidas, estando encuadras en la Relación $n^{\circ}$ 2: material y otros, pasando a la $n^{\circ} 3$ : manutención y asistencia de presos en 1893-94. La cantidad experimenta un notable aumento en el ejercicio de 1893-1894, alcanzando las 200 pesetas, volviendo a descender posteriormente a 150 hasta el final de la centuria. En cuanto a los porcentajes, no dejan de ser mínimos respectos al presupuesto total.

Cuadro 5. Presupuestos de la Cárcel del Partido Judicial de Jerez de los Caballeros en el Periodo de 1867-1900

\begin{tabular}{lccc}
\hline Ejercicio Económico & $\begin{array}{c}\text { Presupuesto } \\
\text { Total }\end{array}$ & $\begin{array}{c}\text { Presupuesto } \\
\text { Medicinas }\end{array}$ & $\%$ \\
\hline $1867-1868$ (en escudos) & $2.400,000$ & - & - \\
\hline $1869-1870$ (en escudos) & $3.000,000$ & - & - \\
\hline $1870-1871$ (en pesetas) & $7.500,00$ & - & - \\
\hline $1875-1876$ (en pesetas) & $7.500,00$ & - & - \\
\hline $1882-1883$ (en pesetas) & $5.684,00$ & - & - \\
\hline $1883-1884$ (en pesetas) & $5.684,00$ & - & - \\
\hline $1884-1885$ (en pesetas) & $5.684,00$ & 100,00 & 1,8 \\
\hline $1885-1886$ (en pesetas) & $5.684,00$ & 50,00 & 0,9 \\
\hline $1886-1887$ (en pesetas) & $4.412,57$ & 96,82 & 2,2 \\
\hline $1887-1888$ (en pesetas) & $4.722,77$ & 96,00 & 2,0 \\
\hline $1889-1890$ (en pesetas) & $4.283,16$ & 25,00 & 0,6 \\
\hline $1893-1894$ (en pesetas) & $8.984,25$ & 200,00 & 2,2 \\
\hline $1896-1897$ (en pesetas) & $7,108,00$ & 150,00 & 2,1 \\
\hline $1897-1898$ (en pesetas) & $9.100,99$ & 150,00 & 1,6 \\
\hline $1898-1899$ (en pesetas) & $15.321,50$ & 150,00 & 1,0 \\
\hline $1899-1900$ (en pesetas) & $10.606,60$ & 150,00 & 1,4 \\
\hline
\end{tabular}

Fuente: AHMJC. Administración de Justicia. Fondos Carcelarios. Presupuesto Carcelario. Legajo 1. Carpetas 1-19. Sin foliar.

Como es lógico resultaba inherente a la mísera existencia de los presos el desarrollo de enfermedades de diversa índole. Ya hemos la preocupación del Ayuntamiento y del Gobierno Civil por estas posibilidades, sobre todo por las enfermedades infectocontagiosas y epidémicas que pudiesen transmitirse a la población, por lo cual se tomaban ciertas medidas como: llevar el pelo muy corto, hacerles tomar un baño de limpieza de vez en cuando, la alimentación será sana y en cantidad, usar vestidos vastos sin tin- te para que se vean las manchas, pero estas consideraciones no eran tenidas en cuenta con los enfermos morales, en los cuales el castigo legal suele tomar carácter de venganza. El preso José Pérez Solano es extraditado de Portugal el 14 de febrero del 1840, acusado de sospechas en su conducta moral, aunque posteriormente no se encuentra motivo de delito en España ${ }^{31}$.

Las patéticas condiciones de vida de los detenidos despertaban iniciativas para su socorro y alivio, de esta manera, el 26 de septiembre de 1805, el Capitán General de la Provincia de Extremadura comunica la creación en Madrid el 17 de agosto, mediante Real Orden, de una asociación de caridad para atender a estas personas, la cual actuará mediante las Juntas de Beneficencia locales. La asociación denominada el Buen Pastor tenía como objetivos suministrar auxilios espirituales y temporales, y consiguió la mejora de la policía de la cárcel y la Salud Pública de éstas, “...los presos que antes yacían en la inmundicia, en el hambre, en la desnudez, y en un cruel abandono, ahora se vén aseados, vestidos, alimentados y consolados..."32. Habiéndose creado otras semejantes en Zaragoza y Palencia, la intención es instaurar una en Jerez, pero como ya existía en la localidad una asociación de caridad para el auxilio de forasteros pobres y vecinos necesitados, será ésta la encargada de atender a los presos, "...repartiendose respectiva y gustosamente el trabajo que es consiguiente a un fin tan laudable, y aun hasta los artesanos turnan diariamente por gremios pidiendo limosna por las calles para los encarcelados"32.

Debido a las espantosas condiciones de la prisión, los reos usaban con frecuencia sus enfermedades, reales o no, para ser trasladados al Hospital, donde poner sanar o tener mejores condiciones de vida.

Otra misión que tenían los facultativos encargados de atender a los presos, era certificar si estaban o no en condiciones de ser trasladados a otra prisión, de esta manera, el 9 de octubre de 1891 se requiere a los médicos cirujanos titulares D. Justo Treviño Botello y D. José Benítez Liñón para que se personen inmediatamente en la prisión para asistir a la reclusa Amalia García Cardenal, y certificar si padece alguna enfermedad que le impida ser conducida a Badajoz. Los médicos certifican "...que padece una fiebre catarral que le precisa guardar cama, habiéndose dispuesto los auxilios que la ciencia aconseja; y que es perjudicial para su salud la traslación de aquella por ahora á la Capital y hasta tanto no desaparezca la enfermedad"33. Así, a la vista de esta declaración se decide suspender la conducción, debiendo informarse cada tres días del estado de la paciente. El 13 de octubre 
continúa la fiebre con bastante intensidad, por lo que sigue siendo desaconsejable el traslado. Finalmente el 16 remite la patología, por lo que los médicos creen que en breves días podrá abandonar el reposo.

Lamentablemente casi nada sabemos sobre las patologías atendidas o causas de defunción de los reos, suponemos que muchas serían derivadas de las paupérrimas condiciones higiénico-sanitarias del establecimiento: respiratorias, digestivas, epidémicas, etc., amén de las comunes y de las que sufriese la población en general. Uno de los pocos testimonios rescatados es el de la certificación emitida por el médico forense del partido, respecto al preso Manuel Borrachero Méndez, “...el cual debía ser trasladado á la carcel de Badajoz [...], se encuentra enfermo por padecer de Paludismo [...] por esta causa queda en esta carcel hasta nueva orden"34.

Así pues, a modo de conclusión decir que las prisiones españolas en general y la jerezana en particular durante el s. XIX, eran deficitarias en materia de Salud Pública, higiene y seguridad. Los presos como grupo específico de pacientes, presentaban enormes carencias en su estado de salud, viviendo en condiciones inhumanas la mayoría de las veces, existiendo por ello el riesgo de epidemias que afectasen incluso a la población general. Los esfuerzos de las diferentes Corporaciones iban dirigidos más a parchear las deficiencias que a solucionarlas definitivamente, debido a la carencia de recursos económicos.

\section{CORRESPONDENCIA}

\section{FJ Suárez Guzmán}

Centro Penitenciario de Badajoz, Carretera de Olivenza, s/n.

Jerez de los Caballeros. Badajoz.

E-mail: fcojsuarez@telefonica.net

\section{REFERENCIAS BIBLIOGRÁFICAS}

1. Marcos-Arévalo J. El Hacinamiento, la Marginación y la Pena de Muerte: La Cárcel de Badajoz en el siglo XIX. Departamento de Publicaciones de la Excma. Diputación de Badajoz. Badajoz; 1984. p. 35.

2. D. Marginados Sociales. Fundación FOESSA. Revista de Documentación Social. $3^{\text {a }}$ Época, 2. Abril-Junio; 1971.

3. AHMJC. Solicitudes. Cárcel. Legajo 1. Carpeta 4. Sin foliar.
4. Madoz P. Diccionario Geográfico-EstadísticoHistórico de España y sus Posesiones de Ultramar. Tomo IX. Estudio Literario-Tipográfico de Madoz y Sagasti. Madrid; 1847. p. 626.

5. Sánchez-Granjel L. La Medicina Española del siglo XVIII. En Historia de la Medicina Española. Vol. IV. Universidad de Salamanca. Salamanca; 1979. p. 120.

6. AHMJC. Obras Públicas y Urbanismo. Obras Públicas. Legajo 2. Carpeta 31. Sin foliar.

7. Ibídem. Carpeta 36. Sin foliar.

8. Ibídem. Carpeta 52. Sin foliar.

9. Monlau PF. Elementos de Higiene Pública o Arte de Conservar la Salud de los Pueblos. Segunda Edición. Imprenta y Estereotipia de M. Rivadeneya. Madrid; 1862. p. 57-60.

10. AHMJC. Gobierno Local. Libros de Acuerdos de Plenos. Legajo 29. Carpeta 191. Fol. 62.

11. Ibídem. Administración de Justicia. Cárcel y Presos. Legajo 1. Carpeta 2. Sin foliar.

12. Ibídem. Carpeta 13. Sin foliar.

13. Rodríguez-Sánchez A. Morir en Extremadura. La Muerte en la Horca a Finales del Antiguo Régimen (1792-1909). Institución Cultural "El Brocense”. Cáceres; 1980. p. 24 y 30.

14. AHMJC. Administración de Justicia. Fondos Carcelarios. Presupuesto Carcelario. Legajo 1. Carpeta 20. Sin foliar.

15. Colección Legislativa de Cárceles. Formada por orden de la Dirección General de Establecimientos Penales. Imprenta Nacional. Madrid; 1860. p. 204.

16. AHMJC. Administración de Justicia. Cárcel y Presos. Legajo 1. Carpeta 21. Sin foliar.

17. Ibídem. Carpeta 12. Sin foliar.

18. Ibídem. Fondos Carcelarios. Presupuesto Carcelario. Legajo 1. Carpeta 1. Sin foliar.

19. Sánchez-Granjel L. El Ejercicio Médico. Universidad de Salamanca. Salamanca; 1974. p. 36.

20. AHMJC. Administración de Justicia. Fondos Carcelarios. Presupuesto Carcelario. Legajo 1. Carpetas 1-20. Sin foliar.

21. Ibídem. Cárcel y Presos. Legajo 1. Carpeta 3. Sin foliar.

22. Ibídem. Gobierno Local. Libros de Acuerdos de Plenos. Legajo 282. Carpeta 144. Fol. 23.

23. Ibídem. Administración de Justicia. Cárcel y Presos. Legajo 1. Carpeta 14. Sin foliar.

24. Marcos-Arévalo J. El Hacinamiento, la Marginación y la Pena de Muerte: La Cárcel de Badajoz en el siglo XIX. Departamento de Publicaciones de la Excma. Diputación de Badajoz. Badajoz; 1984. p. 67-8. 
25. Amador-Fernández MA. La Salud Pública y la Medicina en Almendralejo en el siglo XIX. Tesis Doctoral. Inédita. Universidad de Extremadura. Facultad de Medicina. Badajoz; 2006. p. 1.242.

26. AHMJC. Administración de Justicia. Cárcel y Presos. Legajo 1. Carpeta 10. Sin foliar.

27. Ibídem. Fondos Carcelarios. Presupuesto Carcelario. Carpeta 10. Sin foliar.

28. Ibídem. Cárcel y Presos. Legajo 1. Carpeta 16. Sin foliar.
29. Ibídem. Fondos Carcelarios. Presupuesto Carcelario. Legajo 1. Carpeta 19. Sin foliar.

30. Ibídem. Carpeta 1. Sin foliar.

31. Ibídem. Administración de Justicia. Cárcel y Presos. Legajo 1. Carpeta 6. Sin foliar.

32. Ibídem. Beneficencia y Sanidad. Beneficencia. Legajo 1. Carpeta 2. Sin foliar.

33. Ibídem. Administración de Justicia. Cárcel y Presos. Legajo 1. Carpeta 25. Sin foliar.

34. Ibídem. Prisión "Jerez de los Caballeros". Legajo 1. Carpeta 1. Sin foliar. 